\title{
Pengaruh Penuaan Elektrik terhadap Karakteristik Tegangan Tembus dan PDIV Minyak NanoNynas
}

\author{
Aulia $^{1, *}$, Abdul Manab ${ }^{1}$, Eka Putra Waldi ${ }^{1}$, Muhammad Kodrat ${ }^{1}$, Gusvita Widia ${ }^{2}$ \\ ${ }^{1}$ Jurusan Teknik Elektro, Fakultas Teknik, Universitas Andalas \\ ${ }^{2}$ Jurusan Kimia, Fakultas MIPA, Unversitas Andalas \\ *Corresponding author, e-mail: *aulia.unand@gmail.com
}

\begin{abstract}
Abstrak. Kekuatan dielektrik minyak transformator nynas nitro murni dapat ditingkatkan dengan menambahkan berbagai partikel nano seperti nanoalumina $\left(\mathrm{Al}_{2} \mathrm{O}_{3}\right)$. Penelitian ini bertujuan untuk melihat effek penambahan partikel nano alumina terhadap karakteristik tegangan tembus dan tegangan insepsi peluahan sebagian. Empat jenis minyak nynas dengan komposisi penambahan partikel nanoalumina sebesar $0.00 \%, 0.010 \%, 0.015 \%$ dan $0.020 \%$ diuji tegangan tembus dielektrik, tegangan insepsi peluahan sebagian (PDIV) pada suhu ruang dengan merujuk kepada standar pengujian IEC 60156. Hasil menunjukkan bahwa tegangan tembus minyak nanonynas meningkat sebesar $6 \%$ dan nilai tegangan insepsi dan peluahan sebagian lebih tinggi dibandingkan dengan minyak murni.
\end{abstract}

Kata Kunci : Minyak nynas nitro libra, alumina $\left(\mathrm{AL}_{2} \mathrm{O}_{3}\right)$, tegangan tembus, PDIV

\begin{abstract}
The dielectric strength of pure nynas oil can be enhanced by adding various nanoparticles such as nanoalumina (A12O3). To see the effect of the addition of alumina nanoparticles, 4 types of nynas oil have been prepared with the addition of nanoalumina particles by $0.00 \%, 0.010 \%, 0.015 \%$ and $0.020 \%$. All samples were tested for dielectric breakdown voltage and partial discharge inception voltage (PDIV) test at room temperature with reference to IEC 60156 test standards. The results showed that the nanonynas oil breakdown voltage increased by $6 \%$ and the value of the partial discharge inception voltage also higher than that of pure oil.
\end{abstract}

Keywords : Mineral oil, alumina, brekadown voltage and partial discharge inception voltage

\section{Pendahuluan}

Transformator merupakan komponen penting dari jaringan pembangkit dan distribusi sistem tenaga [1]. Usia dan kinerja transformator daya bergantung pada bahan isolasi lsitrik dan sistem pendingin yang digunakan untuk mengurangi panas yang dihasilkan selama operasi. Minyak transformator mempunyai sifat sebagai isolasi dan media pemindah panas, sehingga dipakai sebagai media pendingin dan isolasi [2]. Sebagai cairan pendingin, minyak transformator mampu memindahkan panas yang dihasilkan di bagian aktif transformator ke lingkungan sekitar. Sebagai isolasi minyak transformator berfungsi mencegah agar tidak terjadi lompatan listrik (flash over) atau percikan (spark over). Sebagai pembuang panas. minyak transformator memiliki konduktivitas termal yang relatif rendah [3], akibatnya kenaikan suhu yang berlebihan akibat overloading menyebabkan kenaikan suhu yang berlebihan sehingga efisiensi minyak sebagai isolasi bisa menurun. Namun di sisi lain isolasi minyak mempunyai beberapa kelebihan dibandingkan isolasi solid yaitu dapat memperbaiki diri sendiri jika terjadi pelepasan muatan. Tetapi dibandingkan dengan isolasi gas bahan isolasi minyak memiliki kekuatan dielektrik yang lebih tinggi karena memiliki kerapatan isolasi 1000 kali lebih besar [4].

Sebagian besar transformator masih diisolasi dengan minyak mineral $[5,6]$. Minyak mineral adalah minyak isolasi yang bahan dasarnya berasal dari minyak bumi yang diproses dengan cara destilasi sehingga mempunyai sifat sebagai isolator dan juga sebagai pendingin [7]. Minyak mineral sulit terurai secara alami oleh migroorganisme dan rentan terhadap bahaya kebakaran [8]. Minyak isolasi mineral banyak digunakan pada transformator daya, kabel, pemutus daya $(\mathrm{CB})$ dan kapasitor [9].

Dalam beberapa dekade terakhir, penggunaan nanopartikel dalam cairan untuk memperbaiki sifat termal telah menarik perhatian ilmuwan. Ide tentang minyak transformator ini akan berguna jika nanopartikel mampu mengurangi dampak 
negatif pada karakteristik listrik dan dielektrik. Dari penelitian sebelumnya menunjukkan bahwa dengan mencampurkan nanopartikel $\mathrm{Al}_{2} \mathrm{O}_{3}$ ke minyak dasar dapat meningkatkan kekuatan tembus minyak dasar [10]. Penelitian nanopartikel dan pengaruhnya terhadap karakteristik dielektrik telah banyak dikaji. Bahan nanopartikel yang dicampur dengan minyak isolasi murni menawarkan proses pendinginan lebih cepat dan ekonomis [11].

Nanofluida merupakan material yang di dalamnya terdapat nano partikel. Penambahan partikel pada cairan dapat memperbaiki kandungan termal, elektrik, dan mekanik [12]. Partikel nano yang berukuran kecil akan mampu meningkatkan daya tahan isolasi dan degradasi minyak transformator sehingga lebih mudah terurai oleh mikroorganisme. Penelitian sebelumnya menyimpulkan bahwa nanofluida memberikan perpindahan panas yang lebih tinggi [13]. Sebagai contoh penambahan nanopartikel ke minyak transformator tidak memiliki pengaruh buruk terhadap ketahanan isolasi minyak dan tegangan tembus [14]. Pada tegangan AC, penambahan nanopartikel dapat meningkatkan sifat dielektrik minyak mineral untuk medan seragam dan medan yang berbeda $[15,16]$. Pada penelitian lain diperlihatkan bahwa nanofluida tidak merubah viskositas secara drastis dibandingkan dengan minyak murni [16].

Kegagalan pada bahan isolasi cair dapat disebabkan oleh adanya kavitasi dan butiran pada zat cair. Kavitasi dan butiran tersebut dapat menyebabkan terjadinya peristiwa peluahan sebagian (PS) yang berdampak pada kinerja transformator secara langsung dan kepada system kelistrikan untuk jangka panjang [17]. Peluahan sebagian adalah salah satu peristiwa yang perlu diperhatikan dalam sistem isolasi cair. Peluahan sebagian merupakan peristiwa pelepasan atau loncatan muatan listrik yang terjadi pada suatu bagian isolasi akibat adanya beda potensial tetapi peluahan tersebut tidak sampai menghubungkan kedua konduktor secara sempurna [18]. Peluahan sebagian dapat terjadi pada bahan isolasi padat, bahan isolasi cair maupun bahan isolasi gas.

Untuk mengembangkan material nanofluida dan mengetahui kekuatan dielektriknya, perlu dilakukan serangkaian pengujian terhadap material tersebut. Hal ini perlu dilakukan untuk melihat sejauh mana persentase penambahan partikel nano memberikan efek terhadap jenis minyak nano yang dikembangkan. Pada penelitian ini dilakukan pengujian tegangan tembus dan tegangan insepsi peluahan sebagian (PDIV) minyak transformator Nynas Nytro Libra (Nynas) yang dicampur dengan partikel nano alumina $\left(\mathrm{Al}_{2} \mathrm{O}_{3}\right)$.

\section{Metoda}

Untuk mengetahui karakteristik tegangan tembus dan PDIV perlu dilakukan penyiapan sampel uji dan sistem pengukuran PS. Minyak yang dipakai adalah minyak nynas yang umum dipakai sebagai bahan isolasi dan sebagai media pendingin pada transformator, sedangkan material nanopartikel yang ditambahkan sebagai bahan pencampur adalah nano alumina. Pengujian tegangan tembus dan pengujian tegangan insepsi peluahan sebagian (PDIV) dilakukan pada suhu ruangan dengan merujuk standar IEC 60615.

\subsection{Persiapan Minyak Nanonynas Alumina}

Bahan yang dipergunakan adalah minyak Nynas Nytro Libra (Nynas) dan 3 buah sampel nanonynas alumina, $\mathrm{Al}_{2} \mathrm{O}_{3}$. Komposisi sampel diperlihatkan pada Tabel 1. Setiap sampel ditimbang sebanyak $0,01 \%, 0,15 \%$ dan $0,02 \% \mathrm{mg}$. Volume minyak murni setiap pengadukan adalah sebanyak 400ml. Sampel nanonynas diaduk selama 12 jam dengan menggunakan stirer elektromagnet pada suhu ruang. Gambar 1. memperlihatkan proses penyiapan sampel minyak nanonynas.

Tabel 1. Komposisi dan kode sampel nanonynas

\begin{tabular}{|c|c|c|c|c|}
\hline \% Alumina & 0.00 & 0.01 & 0.015 & 0.02 \\
\hline Kode Sampel & M000 & M010 & M015 & M020 \\
\hline
\end{tabular}

\subsection{Pengujian Tegangan Tembus}

Pengujian tegangan tembus AC dilakukan dengan merujuk pada standar IEC 60156. Rangkaian pengujian diperlihatkan pada gambar 2. Tegangan input dikontrol dengan menggunakan regulator tegangan. Transformator yang digunakan memiliki perbandingan $2 \times 220 \mathrm{~V} / 100 \mathrm{kV}$ dengan daya nominal 7,5 kVA terhubung ke resistor yang berfungsi untuk melindungi transformator dari kemungkinan terjadinya arus balik yang diakibatkan tegangan tembus. Kapasitor yang digunakan adalah type TK 100-1, dengan tegangan maksimum $100 \mathrm{kV}$ dan kapasitansi $1 \mathrm{nF}$. Osiloskop Tektronix DPO 4104B berfungsi sebagai data akusisi, penyimpan data sehingga gelombang hasil pengukuran dianalisa dan disimpan. 


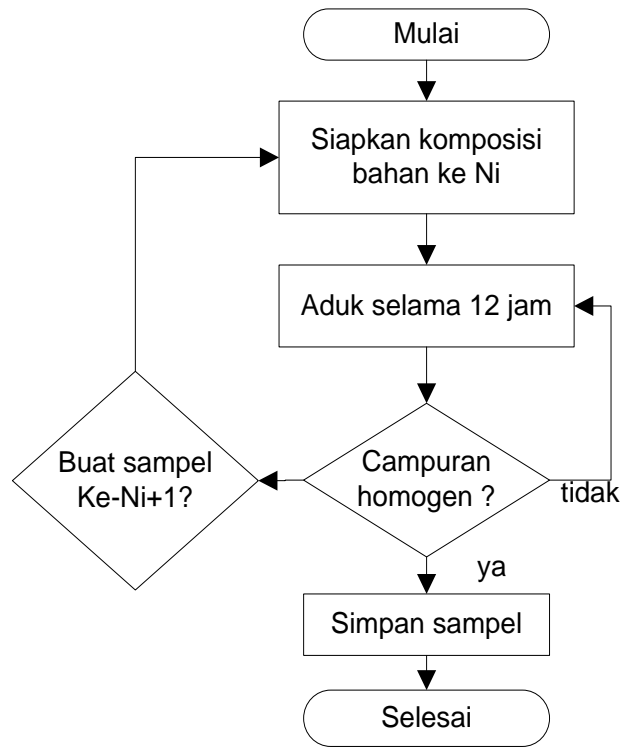

Gambar 1. Proses penyiapan sampel nanofluida Nynas

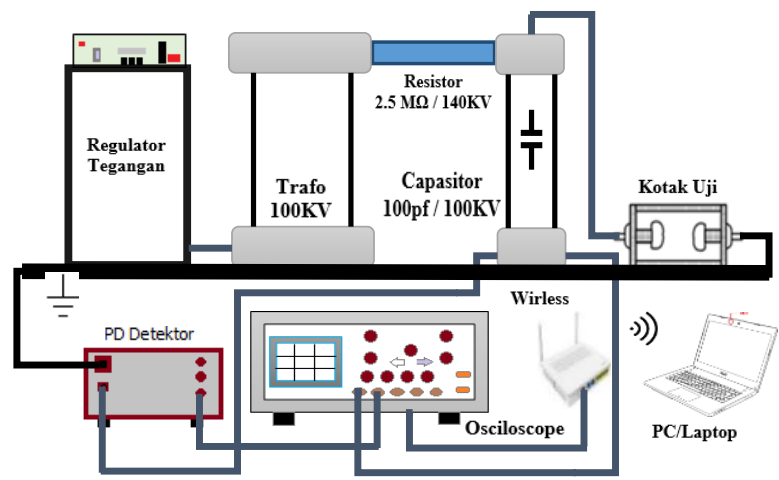

Gambar 2. Rangkaian pengujian tegangan tembus dan PDIV minyak transformator

Tegangan lebih yang dibangkitkan dapat menyebabkan kerusakan pada transformator, untuk memproteksinya ditambahkan spare gap. Elektroda uji yang digunakan permukaanya berbentuk kulit bola yang terbuat dari tembaga kuningan dengan diameter $40 \mathrm{~mm}$ dan panjang 85 mm. Lebih lengkap lihat gambar 2. Jarak celah adalah 2,5mm seperti terlihat pada gambar 3 . Kotak uji berfungsi mewadahi minyak dan sebagai penyangga elektroda. Kotak uji yang digunakan terbuat dari bahan acrylic berbentuk kubus dengan tebal acrylic $100 \mathrm{~mm}$ dan diameter kotak uji: lebar $74 \mathrm{~mm}$, panjang $70 \mathrm{~mm}$ dan tinggi $130 \mathrm{~mm}$. Setiap data diambil perdua menit dan perekaman data menggunakan komputer yang terhubung ke osiloskop secara nirkabel.

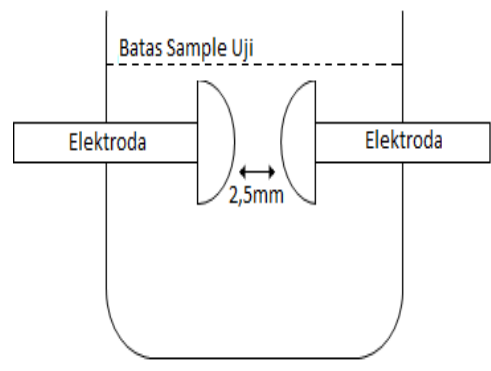

Gambar 3. Komposisi elektroda pengujian tegangan tembus dan PDIV minyak transformator

\section{Hasil dan Pembahasan}

\subsection{Tegangan Tembus AC}

Gambar 4 memperlihatkan hasil pengujian terhadap 4 jenis minyak nynas yang berbeda akibat penambahan nanopartikel alumina $\left(\mathrm{Al}_{2} \mathrm{O}_{3}\right)$ dengan persentase yang berbeda. Tegangan tembus diujikan pada 3 kondisi, kondisi pertama tanpa proses penuaan elektrik, proses ke-2 setelah penuaan elektrik 30 menit dan yang terakhir adalah proses penuaan 60 menit. Tegangan yang diaplikasikan selama proses penuaan adalah sebesar $8 \mathrm{kV}$. Tegangan ini dipilih setelah mengamati pada tegangan tersebut sudah muncul aktifitas peluahan sebagian (PS). Proses Penuaan elektrik seperti ini dapat juga disebut dengan penuaan peluahan sebagian.

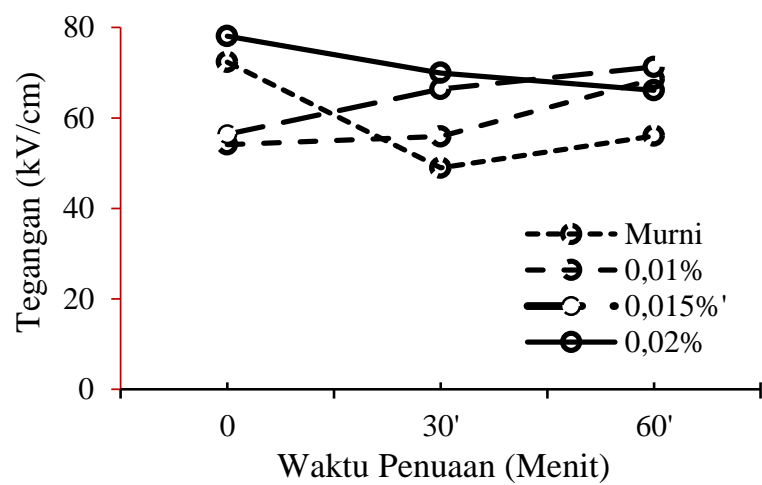

Gambar 4. Tegangan Tembus $(\mathrm{kV} / \mathrm{cm}) 4$ jenis minyak nynas nitro sebelum dan sesudah penuaan tegangan $\mathrm{AC} 8 \mathrm{kV}$

Sebelum proses penuaan, tegangan tembus minyak murni nynas adalah $72 \mathrm{kV} / \mathrm{cm}$. Nilai ini sedikit lebih rendah dibandingkan dengan tegangan tembus minyak nanonynas alumina $0,02 \%$ sebesar $6 \%$, tetapi tegangan tembus minyak 
nynas murni lebih tinggi dari minyak nanonynas $0,01 \%$ dan $0,15 \%$. Setelah mengalami penuaan selama 30 menit tegangan tembus minyak nynas murni dan nanonynas $0,02 \%$ menurun dan nynas murni mengalami penurunan yang signifikan dibandingkan nanonynas $0,02 \%$. Sebaliknya tegangan tembus nanonynas $0,01 \%$ dan $0,015 \%$ bertambah besar, hal ini hanya mungkin terjadi jika medan listrik yang diaplikasi tersebut dipergunakan untuk memperbaiki kualitas campuran minyak nanonynas dan mengakibatkan peningkatan resistansi bahan dielektrik pada kedua bahan nanonynas alumina tersebut. Setelah proses penuaan 60 menit, magnitudo tegangan tembus minyak nanonynas $0.01 \%$ dan $0.015 \%$ alumina terus meningkat secara konsisten, begitu juga minyak murni dan nanonynas $0,02 \%$. Ini mengindikasikan peningkatan resistansi semua jenis minyak nynas terhadap medan listrik AC.

\subsection{Tegangan Insepsi Peluahan Sebagian}

Tegangan insepsi peluahan sebagian (PDIV) minyak nanonynas murni dan nanonynas alumina sebelum dilakukan penuaan dapat dilihat pada gambar 5. Setelah proses penuaan selama 30 menit, semua jenis minyak mengalami penurunan PDIV kecuali minyak nanonynas dengan campuran alumina $0,015 \%$ yang mangalami kenaikan dari $26 \mathrm{kV} / \mathrm{cm}$ menjadi $41 \mathrm{kV} / \mathrm{cm}$. Dapat dilihat bahwa PDIV minyak nynas dipengaruhi oleh persentase kandungan nano alumina dan lamanya proses penuaan. Semua nilai PDIV nanonynas alumina dan minyak murni meningkat setelah proses penuaan 60 menit, tetapi nilai tersebut lebih rendah dibandingkan PDIV tampa proses penuaan kecuali untuk minyak nanonynas $0.015 \%$.

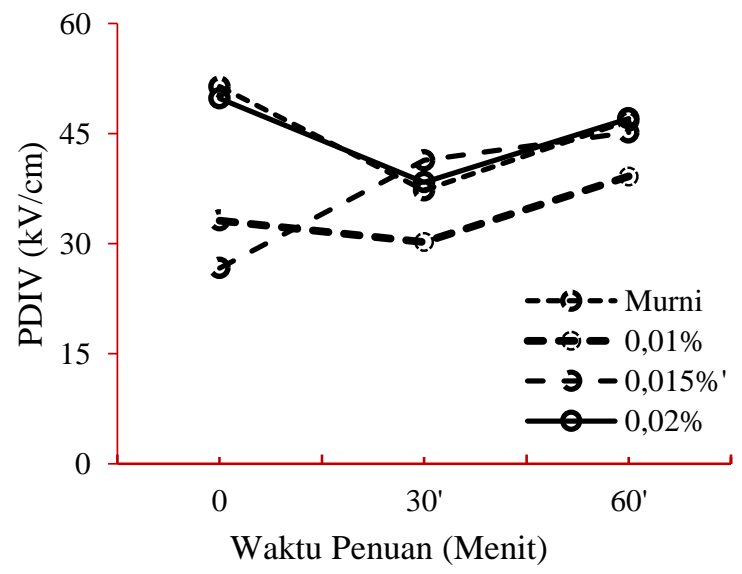

Gambar 5. Tegangan insepsi peluahan sebagian PDIV $(\mathrm{kV} / \mathrm{cm})$
Peningkatan PDIV disebabkan nanopartikel dapat pengontrol dan mengurangi kebebasan pergerakan elektron bebas. Hasil ini menunjukan kesamaan dengan hasil penelitian sebelumnya tapi dengan menggunakan partikel nano yang berbeda [19].

\section{Kesimpulan}

Pengujian kekuatan dielektrik terhadap 4 jenis isolasi minyak transformator nynas telah berhasil dilakukan. Hasil memperlihatkan bahwa penambahan nanopartikel alumina $\left(\mathrm{Al}_{2} \mathrm{O}_{3}\right)$ dapat meningkatkan ketahanan dielektrik minyak isolasi nynas nitro. Pengujian tanpa proses penuaan dan dengan penuaan elektrik selama 60 menit memperlihatkan bahwa minyak nanonynas alumina dengan konsentrasi $0,02 \%$ memiliki tegangan tembus dan PDIV yang lebih besar dibandingkan minyak nynas murni. Minyak nynas nitro yang mengandung nanopartikel alumina $\left(\mathrm{Al}_{2} \mathrm{O}_{3}\right)$ dapat menjadi alternatif untuk dijadikan bahan isolasi minyak transformator di masa yang akan datang.

\section{DAFTAR PUSTAKA}

[1] P. G. Scholar and R. T. A. R. Prasath, "Enhancement of Critical Properties of Pure and Aged Transformer Oil Using Nanocomposites," pp. 382-387, 2014.

[2] D. A. Arifianto, I. Soemarwanto, and I. H. Purnomo, "Analisis Kegagalan Transformator Di PT Asahimas Chemical Banten Berdasarkan Hasil Uji DGA Dengan Metode Roger 's Ratio," Student J., vol. 1-6, no. 2, 2013.

[3] F. O'Sullivan et al., "A model for the initiation and propagation of positive streamers in transformer oil," Conf. Rec. IEEE Int. Symp. Electr. Insul., no. 1, pp. 210-214, 2008.

[4] A. I. Hafez, N. S. Gerges, H. N. Ibrahim, W. S. I. Abou El-magd, and A. I. Hashem, "Evaluation of kaolin clay as natural material for transformer oil treatment to reduce the impact of ageing on copper strip," Egypt. J. Pet., vol. 26, no. 2, pp. 533-539, 2017.

[5] T. A. Prevost and T. V. Oommen, 
"Cellulose insulation in oil-filled power transformers: Part I - History and development," IEEE Electr. Insul. Mag., vol. 22, no. 1, pp. 28-34, 2006.

[6] T. O. Rouse, "Mineral insulating oil in transformers," IEEE Electr. Insul. Mag., vol. 14, no. 3, pp. 6-16, 1998.

[7] M. S. Mohamad, H. Zainuddin, S. A. Ghani, and I. S. Chairul, "Breakdown and Partial Discharge Performance of Palm Fatty Acid Ester (PFAE) Oil - based Fe 3 O 4 Nanofluids," pp. 317-321, 2016.

[8] A. Rajab et al., "Partial discharge phase distribution of palm oil as insulating liquid," Telkomnika, vol. 9, no. 1, pp. 151160, 2011.

[9] I. N. Anggraini and M. K. A. Rosa, "Analisa Tegangan Tembus Minyak Nabati Dengan Perlakuan Pemanasan Berulang," 1982.

[10] M. Rafiq, C. Li, I. Khan, H. Zhifeng, Y. Lv, and K. Yi, "Preparation and breakdown properties of mineral oil based alumina nanofluids," Proc. 2015 Int. Conf. Emerg. Technol. ICET 2015, pp. 2-4, 2016.

[11] Y. Xuan and W. Roetzel, "Conceptions for heat transfer correlation of nanofluids," Int. J. Heat Mass Transf., vol. 43, no. 19, pp. 3701-3707, 2000.

[12] V. A. Primo, B. Garcia, and J. C. Burgos, "Applicability of nanodielectric fluids to the improvement of transformer insulation properties," Proc. 2016 IEEE Int. Conf. Dielectr. ICD 2016, vol. 1, pp. 76-79, 2016.

[13] G. Lazarus, "Nanofluid heat transfer and applications," J. Therm. Eng., vol. 1, no. 2, p. 113, 2015.

[14] V. Segal, A. Hjortsberg, A. Rabinovich, D. Nattrass, and K. Raj, "AC $(60 \mathrm{~Hz})$ and impulse breakdown strength of a colloidal fluid based on transformer oil and magnetite nanoparticles," Conf. Rec. 1998 IEEE Int. Symp. Electr. Insul. (Cat. No.98CH36239), vol. 2, pp. 619-622, 1998.

[15] R. Karthik, F. Negri, and A. Cavallini, "Influence of ageing on dielectric characteristics of silicone dioxide, tin oxide and ferro nanofluids based mineral oil," Proceeding IEEE - 2nd Int. Conf. Adv. Electr. Electron. Information, Commun. Bio-Informatics, IEEE - AEEICB 2016, pp.
40-43, 2016.

[16] M. Bakrutheen, R. Karthik, and R. Madavan, "Investigation of critical parameters of insulating mineral oil using semiconductive nanoparticles," Proc. IEEE Int. Conf. Circuit, Power Comput. Technol. ICCPCT 2013, pp. 294-299, 2013.

[17] H. Illias, T. S. Yuan, A. Halim, A. Bakar, G. Chen, and P. L. Lewin, "Partial Discharge Patterns in High Voltage Insulation," no. December, pp. 2-5, 2012.

[18] E. S. Sitorus, Henry B. H., Diah Permata, "Jurnal Rekayasa dan Teknologi Elektro," Electrician, vol. 2, no. 1, pp. 1-10, 2008.

[19] M. Rafiq, Y. Lv, C. Li, and K. Yi, "Effect of different nanoparticle types on breakdown strength of transformer oil," Annu. Rep. - Conf. Electr. Insul. Dielectr. Phenomena, CEIDP, vol. 2016-Decem, no. 2, pp. 436-440, 2016.

\section{Biodata Penulis}

Aulia Menamatkan pendidikan S1 di Universitas Sriwijaya, Indralaya, Sumatera Selatan jurusan Teknik Elektro. Pendidikan S2 dan S3 diselesaikan tahun 2009 dan tahun 2016 di Universiti Teknologi Malaysia, Johor, Malaysia di bidang Teknik Elektro, khususnya Teknik Tegangan Tinggi. Ketertarikan penelitian adalah di bidang Deteksi Petir, nanokomposit untuk isolasi listrik tegangan tinggi, peluahan sebagian dan energi terbarukan dari panas matahari. Dia telah mempublikasikan puluhan makalah di beberapa jurnal dan seminar berskala internasional dan nasional.

Abdul Manab, Menyelesaikan pendidikan diploma DIII tahun 2009 di Politeknik Negeri Universitas Andalas Jurusan Teknik Elektro Program Studi Teknik Elektronika. Menamatkan S1 di Universitas Palembang, Sumatera Selatan Jurusan Teknik Elektro tahun 2014. Saat ini sedang menyelesaikan pendidikan S2 di Jurusan Teknik Elektro Fakultas Teknik Universitas Andalas, Sumatera Barat. Bidang yang ditekuni adalah teknik tegangan tinggi khususnya isolasi cair dan nanofluida.

Eka Putra Waldi Menyelesaikan pendidikan S1 tahun 1997 di Universitas Sriwijaya, Indralaya, Sumatera Selatan. Pendidikan S2 diselesaikan di Toyohashi University, Jepang tahun 2004 dan S3 
di Unversitas Andalas tahun 2018 di bidang teknik tegangan tinggi. Ketertarikan penelitian adalah di bidang deteksi petir, isolasi listrik tegangan tinggi dan peluahan sebagian.

Muhammad Kodrat. Saat ini sedang menempuh pendidikan studi S1 di Jurusan Teknik Elektro
Fakultas Teknik Universitas Andalas. Program Studi Teknik Tegangan Tinggi.

Gusvita Widia. Saat ini sedang menempuh pendidikan study S1 di Jurusan Kimia Fakultas Matematika dan Ilmu Pengetahuan Alam Universitas Andalas. Program Studi Kimia Material. 